\title{
Experimental Evidence for Different Strain Regimes of Crack Populations in a Clay Model
}

\author{
Chrysanthe Spyropoulos \\ Department of Applied Physics and Applied Mathematics, Columbia University, New York, NY.
}

William J. Griffith

Geology Department, Macalester College, St. Paul, MN

Christopher H. Scholz and Bruce E. Shaw

Lamont Doherty Earth Observatory, Columbia University, New York, NY.

\begin{abstract}
We report results from clay extension experiments used as a model for the evolution of fault populations due to stress interactions. At yielding cracks begin to appear and the brittle strain due to them quickly reaches a rate matching the applied stretching rate. The crack density (number of cracks per unit area) initially increases apace, then reaches a maximum at a critical strain, decreasing thereafter. At low strains, where the crack population is dilute, a power law length distribution is observed, which at high strain, gradually transitions to an exponential. This agrees with fault populations data observed in low and high strain settings. These results indicate that fault populations ranging from power law to exponential size-frequency distributions reflect the population evolution with increased strain.
\end{abstract}

\section{Introduction}

Fault populations often obey a power-law size distribution e.g. [Scholz et al., 1993], but fault populations with exponential distributions have also been observed [Cowie et al., 1993]. An important question is identifying the mechanisms that control how faults organize themselves into such populations both at the surface, where they can be observed, as well as at the subsurface, where one would have to infer their distribution.

Nucleation of faults may occur anywhere rock is locally weak. As strain increases the population of faults increases. Faults propagate and some begin to coalesce [Peacock and Sanderson, 1991] forming larger faults. As a fault slips the stress accumulated at the surrounding area is relieved [Ellis and Dunlap, 1988; Sornette and Davy, 1991; Cowie and Scholz, 1992; Scholz et al., 1993]. A reduced stress zone develops [Lachenbruch, 1961; Nur, 1982; Pollard and Segall, 1987; Gross, 1993] such that fault nucleation and further growth of exist-

Copyright 1999 by the American Geophysical Union.

Paper number 1999GL900175.

0094-8276/99/1999GL900175\$05.00 ing smaller faults is inhibited within it [Ackermann and Schlische, 1997]. Eventually the faults extend as deep as the brittle layer, forming a shadow zone whose width scales with the thickness of the brittle layer. The brittle layer saturates with faults of lengths many times the brittle thickness and with spacings proportional to that thickness. The question we address here is how does the crack population evolve in the pre-saturation regime?

The above mechanisms are similar to those involved in the growth of joints (Mode I cracks) [Hu and Evans, 1989; Narr and Suppe, 1991; Gross, 1993; Wu and Pollard, 1995; Vermilye and Scholz, 1995]. The similarities between Mode I and Mode III cracks as far as the above mechanisms are concerned may be argued by examining their stress fields in the plane of propagation. The stress field of a Mode I crack in the plane of propagation resembles a quadrapole-like configuration with a high tensile stress concentration at the tips and a symmetrical stress relaxation on either side. Similarly a Mode III crack stress field has the same features for its driving stress, an anti-plane shear stress in that case [Pollard and Segall, 1987]. The stress fields of these two modes should interact in equivalent ways and give rise to similar crack populations. Hence, experimental studies of the evolution of population of joints may be extended with some care to explain interactions of populations of normal faults. In this paper we consider such a possible explanation for the different frequencysize distributions observed in fault data, using a model of tensile cracks formed in a clay layer under extension.

Geological data on fault populations is usually very band-limited, so it is often difficult to decide if the size distribution is power law or exponential [Cladouhos and Marrett, 1996]. Where the data do show an unequivocal power law [Scholz et al., 1993; Scholz, 1997] the brittle strain is $1-2 \%$, but in the cases where the distribution is clearly exponential [Cowie et al., 1993] the strain is much higher (10-15\%). A similar breakdown from a power law size distribution for increasing strain was observed in a numerical model [Spyropoulos, C., Scholz, C.H., Shaw, B.E., Transition regimes for growing crack populations, submitted to Physical Review E, 


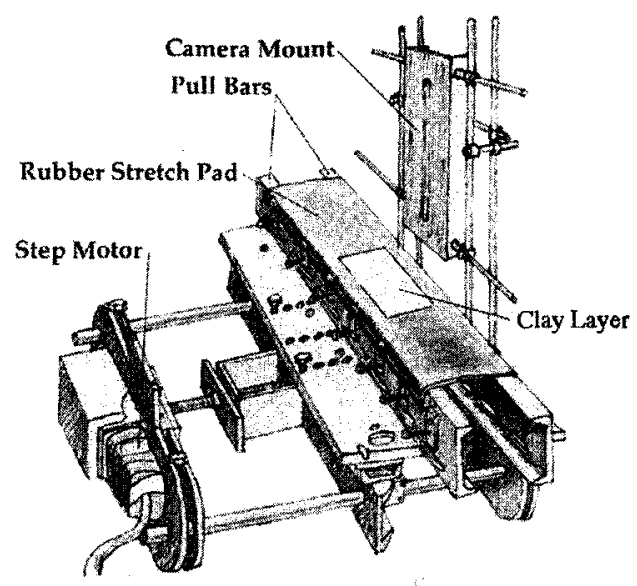

Figure 1. The apparatus consists of a rubber stretch pad clamped on pull bars. The left bar moves outward by a lead screw attached to a stepping motor. The clay layer rests on top of the rubber pad. A digital camera mounts on the right above the clay layer. Sketch by W.J. Griffith

1998]. These observations prompted us to examine the evolution of crack populations with strain in a physical model using a thin layer of clay/water mix. Similar models have been previously studied for Mode II cracks [Sornette A. et al., 1993; Davy et al., 1995] and Mode I cracks [Hu and Evans, 1989; Wu and Pollard, 1995; Walmann et al., 1996] however they did not investigate the evolution of the frequency size-distribution as a function of strain, which is the main topic of this letter.

\section{Experimental Set Up}

A clay layer was applied to a $2.54 \mathrm{~mm}$ thick rubber stretch pad clamped to two metal pull bars. Fig. 1 shows a sketch of the experimental apparatus. The left pull bar was attached to a stepping motor via a lead screw which extended the rubber pad. Clay samples were mixed from Grolleg Quality China Clay and water in a 2.75:1 clay to water mass ratio. Samples near this ratio exhibited enough brittleness so that there was distributed cracking. Much drier samples showed immediate parting of the whole sample, whereas much wetter samples deformed without cracking. A digital video camera was attached to the camera mount. A $750 \mathrm{~W}$ photographer's lamp directed at an oblique angle and a "shield" were used to cast shadows of the cracks' openings that made them visible for recording. The data shown here are for a clay layer thickness of $0.8 \mathrm{~mm}$. Crack spacing increases with layer thickness and microscopic examination showed that the smallest cracks observable were about two layer thicknesses long. Therefore, the results shown hear are for the thinnest layers practicable, because that provided the greatest range in crack length and numbers.
Each run was recorded by the camera and then captured with NIH Image software. The captured image was thresholded and converted to a binary image which was used for further image analysis. The velocity of the machine was chosen after exploring the effect of different velocities on the evolution of the crack population. For high velocities there was lack of smaller cracks as deformation was only taken up by a few large ones. For velocities slower than $0.057 \mathrm{~mm} / \mathrm{sec}$ there was convergence of the frequency size distributions. For very slow velocities the consistency of the clay sample was considerably altered by drying which rendered them unsuitable for comparison. The experiments were run at a velocity of $0.057 \mathrm{~mm} / \mathrm{sec}$ (i.e. an approximate strain rate of $0.0137 \% / \mathrm{sec}$ ) so as to insure they were done slow enough not to get runaway cracks but fast enough such that the consistency of the mix would not significantly change by drying. Each run took about 17 minutes.

\section{Observations}

Fig. 2 shows a binary image of the cracks at about $14 \%$ brittle strain. The camera only captures cracks that have reached the surface and extend through the clay layer and are thus only growing in 2-D. 3-D subsurface crack growth can not be detected with this laboratory set up. Increasing the resolution of the image with the aid of a microscope verified that the size of the smallest crack that could be detected was several times the layer thickness. The video resolved all cracks at that size. The brittle strain, $\epsilon_{b}$, is calculated by summing over the opening of the cracks in the sample and dividing that by the total area of the sample. The opening is calculated using the shadowed area cast from each crack, assuming that opening is proportional to that area.

The data shown in Figs. 3 and 4 are stacked and averaged data from 10 experiments. In Fig. 3 the number of cracks per unit area is plotted as a function of brit-

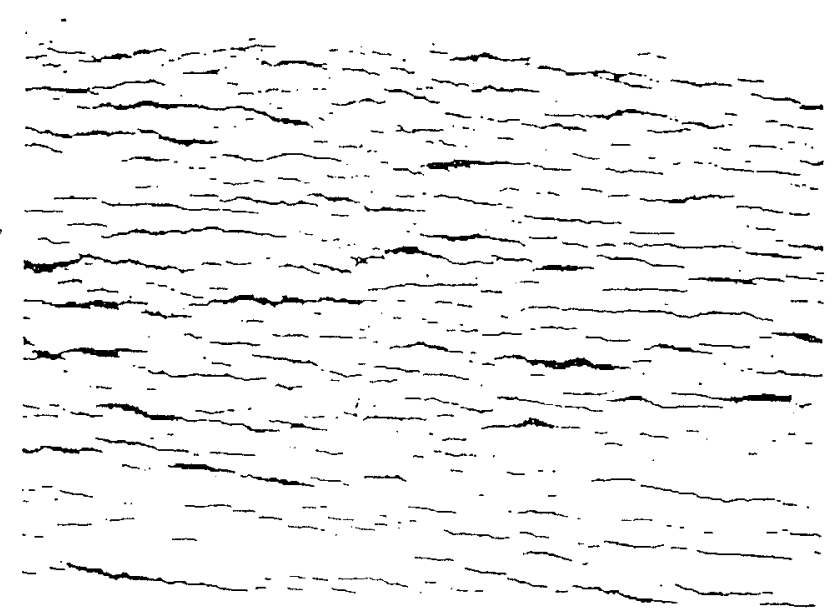

Figure 2. Binary image of the cracks at $14 \%$ brittle strain. 


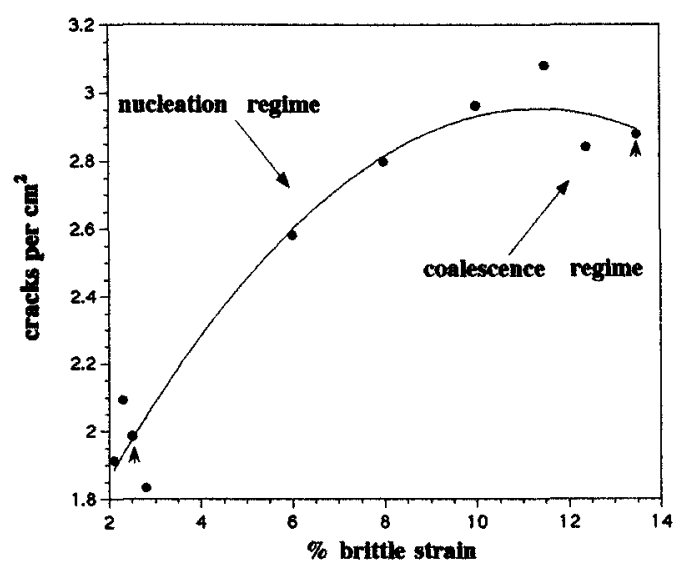

Figure 3. Number of cracks per unit area as a function of brittle strain. Brittle strain is calculated from scaling the shadowed area of all the cracks on a clay sample by the total area. At low strain nucleation dominates in which the crack density rapidly increases with strain. At high strain coalescence begins to dominate nucleation, and the crack density decreases.

tle strain. Although total strain is easily measured in the experiments, scaling the data with brittle strain is a better way to compare them. Small variations in moisture content in different runs lead to variation in the yield strain at which cracks begin to nucleate. Comparing all the data to brittle strain rather than total strain insures that data for different runs can be properly averaged. As the rubber layer extends, elastic and thus brittle strain increase, cracks nucleate and the strain is distributed throughout the clay layer. Initially, the crack density (number of cracks per unit area) increases rapidly, but the rate of nucleation of new cracks gradually decreases until a maximum crack density is reached after which the number of cracks decreases with additional brittle strain.

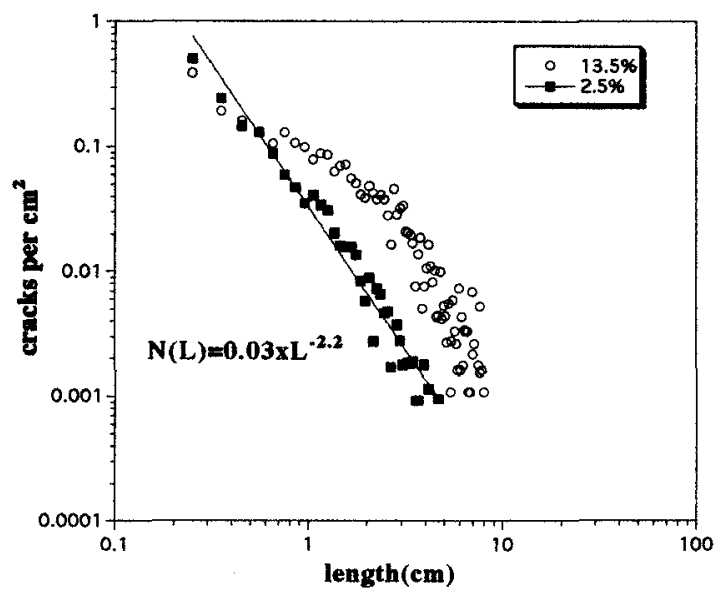

The probability that a crack will nucleate is proportional to the available area where nucleation is allowed to occur. Although initially that area is equal to the total area of the sample it reduces due to stress shadowing. Each crack relaxes the stress a distance proportional to the layer thickness on either side of it [Hu and Evans, 1989] within which the probability of crack nucleation is significantly reduced.

For low strain coalescence rates are small since there are not many cracks which can potentially coalesce to form larger ones. The cracks are sparsely distributed on the clay layer which allows for more cracks to nucleate and the number of cracks to increase. As strain increases coalescence rate also increases. Because nucleation rate decreases with strain and coalescence rate increases, there will be a critical strain, at which coalescence rate exceeds nucleation rate and the number of cracks begins to decrease. These two different phases of the evolution are marked on Fig. 3 as the nucleation regime and the coalescence regime. For even higher strain the number of cracks asymptotes to a fixed number of large system size cracks separated by a distance proportional to the thickness of the brittle layer [Hu and Evans, 1989].

We show the frequency size distributions, the number of cracks per unit area with length between $l$ and $l+d l$, at $2.5 \%$ and $13.5 \%$. Fig. $4 \mathrm{a}$ is a $\log -\log$ plot, with a power law fit for the data at $2.5 \%$ (all data are averaged from 10 experiments). This fit is quite good, with an exponent of about -2.3 . The data at $13.5 \%$ strain is presented in the same plot: it clearly does not define a power law. A log-linear plot for the same data in Fig. 4b shows that the data for $13.5 \%$ strain can be closely described by an exponential function. From Figs. $4 a$ and $4 b$ it is evident that for low strain there are many more small cracks relative to intermediate or

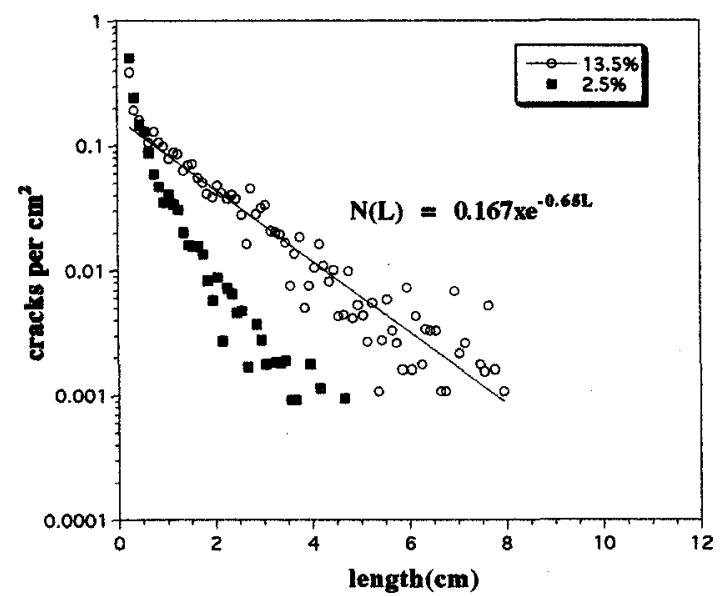

Figure 4. Frequency size distributions averaged over 10 experiments at two different strains plotted on two different scales: a) Log-log scale. One data set is for low brittle strain, $2.5 \%$. The data is fitted with a line of power exponent of -2.28 . The other is for higher brittle strain, 13.5\%. Although this data set is not fitted one clearly observes that it is not a power law. b) Log-linear scale. The low brittle strain data is not fitted - the data is concave and not a straight line. The higher strain data is fitted with a straight line to show that they are approximately an exponential distribution. 
larger sized ones whereas for higher strain the number of cracks of intermediate length has increased relative to the number of cracks of small length. Similar analysis at 5 strain intervals between the two illustrated shows that this is a gradual, not an abrupt, transition.

\section{Discussion}

These observations suggest the following interpretation: The power law distribution, which is expected for self-organized critical systems [Bak et al., 1988], exists only for dilute populations. As soon as the crack density is such that crack interactions become important, they begin to distort this population. The stress shadowing interaction, progressively reduces the nucleation rate, thus starving the populations of small cracks. The coalescence interactions, due to the enhanced stress in front of the crack tips, annihilates small cracks to make larger ones, causing a bloat of intermediate size cracks. These two have the combined effect of distorting the distribution until it eventually resembles an exponential distribution.

\section{Conclusions}

In these experiments the crack populations at low strain exhibit power law size distributions with an exponent for the frequency distributions of about -2.3 . This agrees with observations (and exponents) of normal fault populations at low strain [Scholz et al., 1993; Scholz, 1997]. As strain increases the nucleation rate decreases and the rate of crack coalescence increases, leading to a maximum in crack density. Intermediate to long cracks are encouraged to grow, while the population of small cracks is starved. Eventually the size distribution becomes approximately exponential. This agrees with the distribution of normal faults observed at high strain by Cowie et al. (1993). The same results have also been obtained in a numerical model [Spyropoulos, C., Scholz, C.H., Shaw, B.E., Transition regimes for growing crack populations, submitted to Physical Review E, 1998].

Therefore, one should not expect that fault populations always define either a power law or exponential distribution: there is a gradual evolution of one to the other as brittle strain increases.

Acknowledgments. We are grateful to Ted Koczynski . for invaluable help with building the apparatius and for many excellent suggestions. We thank Katherine Brown for ber early work with this model. We would also like to thank the reviewers of this manuscript for their helpful comments. This work was partially supported by NSF grants EAR9706475 and 94-17700, USGS 1434-HQ-97-6R03074, and by the Center for Nonlinear Earth Systems, Columbia Earth Institute.

\section{References}

Ackermann, R.V. and R.W. Schlische, Anticlustering of small normal faults around larger faults, Geology, 25 1127$1130,1997$.
P. Bak, C. Tang and K. Weisenfeld, Self-organized criticality, Phys. Rev. A, 38, 364-374, 1988.

Cladouhos, T.T., and R. Marrett, Are fault growth and linkage models consistent with power law distributions of fault length?, J. Struct. Geol., 18, 281-293, 1996.

Cowie, P.A. and C.H. Scholz, Growth of faults by the accumulation of seismic slip, J. Geophys. Res., 97, 11,08511,095, 1992.

Cowie, P.A., C.H. Scholz, M. Edwards, and A. Malinverno, Quantitative fault studies on the East Pacific Rise - a comparison of sonar imaging techniques, J. Geophys. Res., Solid Earth 98, 17,911-17,920, 1993.

Davy, P, A. Hansen, E. Bonnet, and S.Z. Zhang,Localization and fault growth in layered brittle-ductile systems - Implications for deformations of the continental lithosphere, J. Geophys. Res., Solid Earth , 100, 6281-6294, 1995.

Ellis, M.A. and W.J. Dunlap, Displacement variations along thrust faults: implications for the development of large faults, J. Struct. Geol., 10, 183-192, 1988.

Gross, M.R., The origin and spacing of cross joints: examples from Monterey Formation, Santa Barbara Coastline, California, J. Struct. Geol., 15, 737-751, 1993.

$\mathrm{Hu}$, M.S. and A.G. Evans, The cracking and decohesion of thin-films on ductile substrates, Acta Metall. Mater., 37, 917-925, 1989.

Lachenbruch, A.H., Depth and spacing of tension cracks, J. Geophys. Res., 66, 4273-4292, 1961.

Narr, N., and J. Suppe, Joint spacing in sedimentary rocks, J. Struct. Geol., 13, 1037-1048, 1991.

Nur, A., The origin of tensile fracture lineaments, J. Struct. Geol., 4, 31-40, 1982.

Peacock, D.C.P. and D.J., Sanderson, Displacements, segment linkage and relay ramps in normal fault zones, $J$. Struct. Geol., 13, 721-733, 1991.

Pollard, D.D. and P. Segall, Theoretical displacements and stresses near fractures in rocks: with applications to joints, veins, dikes and solution surfaces, in Fracture $\mathrm{Me}$ chanics of Rock, Atkinson, B.K., eds, Academic Press, London, 277-349, 1987.

Scholz, C.H., N.H. Dawers, J.Z. Yu, and M.H. Anders, Fault growth and fault scaling laws: Preliminary results, J. Geophys. Res., 98, 21,951-21,961, 1993.

Scholz, C.H., Size distributions for large and small earthquakes, Bull. Seismol. Soc. Am., 87,1074-1077, 1997.

Sornette, D., and P.Davy, Fault growth-model and the universal fault length distribution, seismic slip Geophys. Res. Lett., 97, 1079-1081, 1991.

Sornette, A., P. Davy, and D. Sornette, Fault growth in brittle-ductile experiments and the mechanics of continental collisions, J. Geophys. Res., Solid Earth, 98, 12,11112,139, 1993.

Vermilye, J.M., and C.H. Scholz, Relation between vein length and aperture, J. Struct. Geol., 17, 423-434, 1995.

Walmann, T., A. Malthe-Sorenssen, J. Feder, T. Jossang, P. Meakin, and H.H. Hardy, Scaling relations for the lengths and widths of fractures, Phys. Rev. Lett., $77,5393-5396$, 1996.

Wu, H.Q., and D.D. Pollard, An experimental-study of the relationship between joint spacing and layer thickness, $J$. Struct. Geol., 17, 887-905, 1995.

C. Spyropoulos, Department of Applied Physics and Applied Mathematics, Columbia University, S.W. Mudd, Room 209, Columbia University New York, NY 10027. (email: cspyro@appmath.columbia.edu)

W.J. Griffith, Geology Department, Macalester College, St. Paul, MN 55105. (e-mail: wgriffith@macalester.edu)

C.H. Scholz, B.E. Shaw, Lamont-Doherty Earth Observatory, Columbia University, Palisades, NY 10964. (email: scholz@ldeo.columbia.edu, shaw@ldeo.columbia.edu)

(Received November 3, 1998; revised January 13, 1999; accepted February 23, 1999.) 